\title{
Fatigue resistance of a grid-reinforced asphalt concrete using four-point bending beam test
}

\author{
M. Orešković, S. Trifunović \& G. Mladenović \\ University of Belgrade, Faculty of Civil Engineering, Belgrade, Serbia \\ Š. Bohuš \\ Saint-Gobaint ADFORS CZ s.r.o., Litomyšl, The Czech Republic
}

\begin{abstract}
This paper presents an experimental study of the influence of a reinforcement system on fatigue resistance of asphalt concrete. For purpose of this research, unreinforced and grid-reinforced asphalt specimens were tested. Both groups of specimens were manufactured using non-standard method. A 1-ton roller had been used to prepare two-layered slabs with total height of $70 \mathrm{~mm}$. Further, slabs were sawed to obtain beams $6 \mathrm{~cm}$ wide and $400 \mathrm{~mm}$ long. The total height of each beam was $50 \mathrm{~mm}$, including $20 \mathrm{~mm}$ of the bottom layer and $30 \mathrm{~mm}$ of the upper layer. The reinforced specimens contained self-adhesive geosynthetic grid between layers. The four-point bending beam test, according to EN 12697-24:2012, was used for fatigue testing, while results were analyzed using various failure criteria. The experiment helped to quantify the extension of fatigue life that can be obtained by reinforcement, depending on the selected testing conditions and fatigue criteria.
\end{abstract}

\section{INTRODUCTION}

Road pavements are designed to withstand traffic load during their service life without significant distresses. Due to increasing axle loading, tire pressure and climate change impact on pavements, premature cracking and other distresses may appear. The presence of these distresses has negative impact on the ride quality; hence, it is necessary to repair the damage they cause or to prevent their occurrence.

Two types of cracking are quite widespread: fatigue and reflective. Fatigue cracking is one of the most common distresses in flexible pavements, while reflective cracking is typical for semi-rigid pavements. Coated glass fibre grids (glasgrids) can be used as internal reinforcement in different pavement structures with the aim of reducing cracking (Arsenie et al. 2016). Their application during rehabilitation of existing roads or construction of new roads contributes to delaying crack initiation and propagation (Arsenie et al. 2014).

When flexible pavements are rehabilitated, glasgrids should be placed between the top of the old base course, after milling the wearing course or on a new levelling course. In the case of new semi-rigid pavements, glasgrids should be placed over the smooth cement-treated base course. If a rigid pavement needs to be overlaid with an asphalt layer, it is recommended to place glasgrids below the asphalt layers. These positions of glasgrids, together with the quality of the interface between these two materials, delay and prevent the propagation of cracks from the old pavement and/or rigid courses by dissipating the horizontal stresses induced by the cracks. This way, the fatigue resistance of these pavements is improved (Arsenie et al. 2016, Nguyen et al. 2013).

Nguyen et al. (2013) and Pasquini et al. (2013) carrying out in-situ studies that confirmed the glasgrids delay fatigue cracking propagation. The same results have been obtained in other laboratory studies, under different testing conditions, using three-point bending (3PB) tests on beams (Graziani et al. 2016, Romeo \& Montepara 2012) and slabs (Romeo \& Montepara 2012), as well as four-point bending (4PB) and 3PB fatigue tests (Arsenie et al. 2016, Arsenie et al. 2014, Pasquini et al. 2013, Virgili et al. 2009).

The research presented in this paper evaluates the influence of glasgrids on fatigue resistance of doublelayered asphalt beams. For this purpose, two groups of specimens (unreinforced and grid-reinforced) were tested using the $4 \mathrm{~PB}$ fatigue test. The obtained results were analysed using two failure criteria (50\% reduction of the initial complex modulus, i.e. the conventional approach, and the energy ratio approach).

\section{MATERIALS AND METHODS}

\subsection{Asphalt mixture}

All slabs compacted for the production of the 4PB specimens were produced using the same mixture: a dense graded mix with a maximum aggregate size of $11.2 \mathrm{~mm}$ (AC 11) and polymer-modified bitumen PmB 45/80-65. Crushed mineral aggregate fractions 
were of igneous origin, except the sand, which was limestone. The composition of the asphalt mixture with proportions of component materials is presented in Table 1.

Table 1. Proportions of the component materials in the mix

\begin{tabular}{ll}
\hline Material type & Asphalt mixture \\
\hline Stone filler & $5.2 \%$ \\
Limestone sand $0 / 2 \mathrm{~mm}$ & $29.1 \%$ \\
Crushed aggregate $2 / 4 \mathrm{~mm}$ & $16.6 \%$ \\
Crushed aggregate $4 / 8 \mathrm{~mm}$ & $24.7 \%$ \\
Crushed aggregate $8 / 11 \mathrm{~mm}$ & $19.4 \%$ \\
Bitumen PmB $45 / 80-65$ & $5.0 \%$ \\
\hline
\end{tabular}

The asphalt mixture required for the production of slabs, as well as for laboratory testing of physical-mechanical properties (Tab. 2), was sampled directly from the hot asphalt storage bin at the asphalt plant.

Table 2. Physical-mechanical properties of the asphalt mixture

\begin{tabular}{lcll}
\hline Properties & Results & Unit & Standard \\
\hline Stability - S & 14.6 & $\mathrm{kN}$ & \\
$\begin{array}{l}\text { Flow - F } \\
\text { Marshal quotient - S/F }\end{array}$ & 3.4 & $\mathrm{~mm}$ & $\mathrm{EN} \mathrm{12697-34}$ \\
$\begin{array}{l}\text { Bulk density - Zm } \\
\text { Maximum density - }\end{array}$ & 2.419 & $\mathrm{Mg} / \mathrm{m}^{3}$ & EN 12697-6 \\
$\begin{array}{l}\text { Zmax } \\
\text { Air voids - Vm }\end{array}$ & 2.553 & $\mathrm{Mg} / \mathrm{m}^{3}$ & EN12697-5 \\
$\begin{array}{l}\text { Voids in mineral aggre- } \\
\text { gate filled with binder - }\end{array}$ & 69.3 & $\%$ [v/v] & \\
$\begin{array}{l}\text { VFB } \\
\text { Voids in mineral aggre- }\end{array}$ & & & \\
gate - VMA & 17.1 & $\%$ EN 12697-8 & \\
\hline
\end{tabular}

\subsection{Reinforcement grid}

The glasgrid used as reinforcement in this study was the knitted coated glass fibre grid of high strength, with a mesh size of $25 \times 25 \mathrm{~mm}$. Both yarn types were made of continuous glass fibre with a Young's Modulus $(E)$ of $73000 \mathrm{MPa}$ and coated with an elastomeric polymer (with a Coating Melting Point higher than $230{ }^{\circ} \mathrm{C}$ ) for glass fibre protection and asphalt layer bonding enhancement. The mechanical strength at failure of this glasgrid is $115 \times 115+/-15 \mathrm{kN} / \mathrm{m}$.

In practice, the glasgrid is installed using a selfadhesive glue, which is part of the grid backing, and later bonded to the pavement layers with an emulsion $\left(>0.25 \mathrm{~kg} / \mathrm{m}^{2}\right)$ and a coating crosslinking to the asphalt layers.

\subsection{Sample preparation}

Six slabs (three without and three with glasgrid hereafter referred to as unreinforced (URF) and reinforced (RF), respectively), with dimensions of $500 \times$ $500 \times 70 \mathrm{~mm}$, were compacted in metal moulds using a non-standardized method: a one-ton roller compactor (Fig. 1a).

The 30-mm thick bottom layer was compacted first. After the asphalt mixture cooled down, the glasgrid was placed on every other slab and pressed by several roller passes to ensure adhesion between the grid and the asphalt surface (Figs. 1b-1c). The 40-mm thick upper layer was then laid over the prepared slabs. Although a bitumen emulsion is typically applied between layers, it was not used within this study. The upper layer was laid and compacted over the warm bottom layer, only a couple of hours after its compaction.

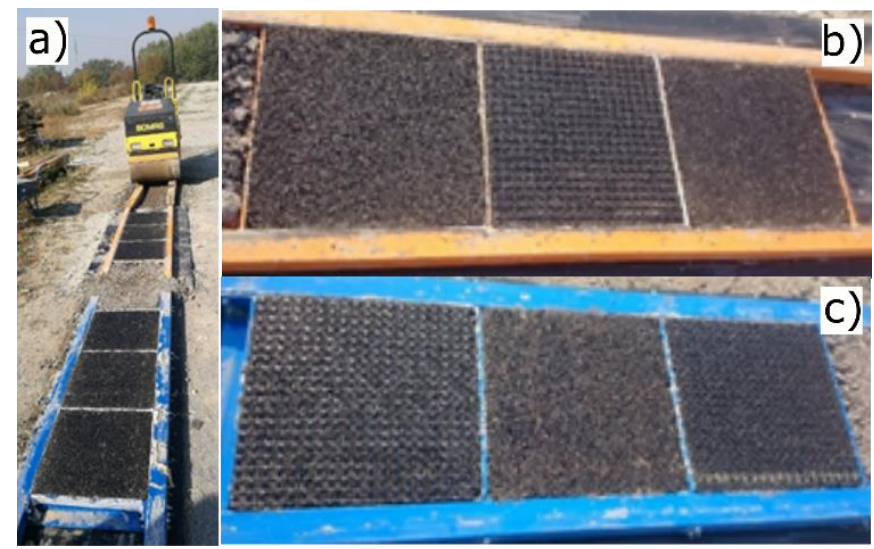

Figure 1. (a) Compaction of slabs with a 1-ton roller and (b, c) compacted bottom layers with and without glasgrid

Two days after compaction, slabs were removed from moulds and sawed in order to obtain six beams from each slab to satisfy requirements of EN 1269724:2012, Annex D. Beams were $60 \mathrm{~mm}$ wide and 400 $\mathrm{mm}$ long. The total height of each beam was $50 \mathrm{~mm}$, including $20 \mathrm{~mm}$ of the bottom layer and $30 \mathrm{~mm}$ of the upper layer (Fig. 2). Two sets of 18 specimens each were prepared for both the RF and URF sets.
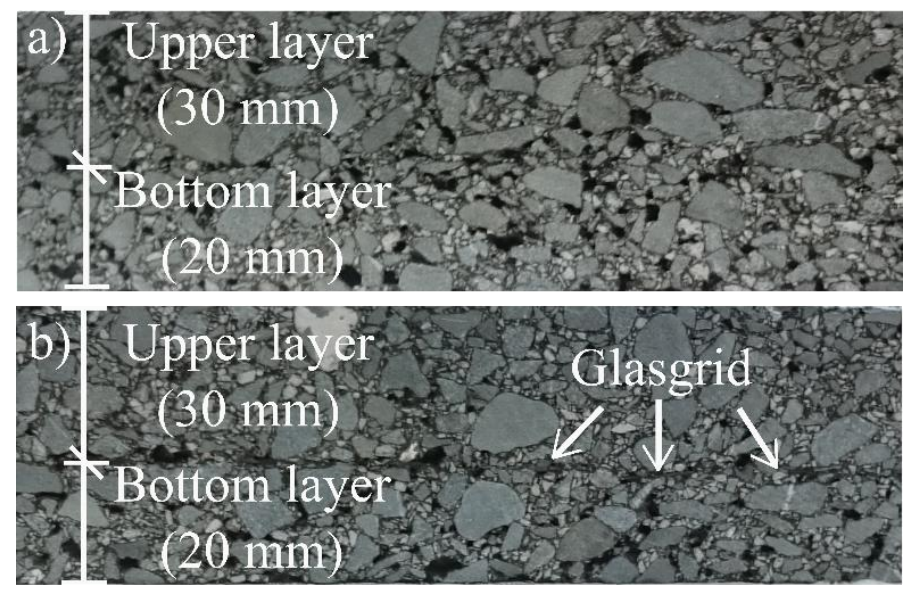

Figure 2. Cross sections of (a) URF and (b) RF beams

Nine specimens from each set were chosen to obtain three comparable subsets with the most similar volumetric properties for fatigue testing, while the remaining specimens were used for pre-testing. 


\subsection{Fatigue test procedure}

In this study, a 4PB fatigue test in a stress-controlled mode was used to determine the influence of reinforcement on the fatigue life. The fatigue tests were carried out using a standard 4PB device, at three stress levels: $0.850,0.650$ and $0.550-0.590 \mathrm{MPa}$. The beams were exposed to bending with a continuous 10 $\mathrm{Hz}$ sinusoidal loading at a temperature of $20{ }^{\circ} \mathrm{C}$ according to EN 12697-24:2012.

\section{CHARACTERIZATION OF FATIGUE LIFE}

Several criteria are used to estimate the fatigue life of bituminous materials; however, the traditional approach using a 50\% reduction of the initial complex modulus (conventional approach) and energy ratio (ER) approach were used in this study.

Since glasgrids should dissipate the horizontal stresses induced by the cracks, it was decided to compare fatigue life obtained using these two approaches. The conventional approach is one of the most widespread failure criteria, and the ER approach has also been widely used since it is not sensitive to the initial value of stiffness or cycles (Rowe et al. 2012) and it may show longer fatigue life compared with the traditional approach (Abojardeh 2013), whereas the fatigue life according to the conventional approach may be achieved before the crack initiation (Rowe 1993).

\subsection{Conventional approach using a 50\% reduction of the initial complex modulus}

The conventional approach developed by Van Dijk \& Visser (1977) has defined a failure as the number of cycles $(\mathrm{Nf})$ at which the specimen complex modulus is reduced to $50 \%$ of its initial value (usually defined as the stiffness at the 100th cycle) (Fig. 3). Although this approach is relatively simple, it has certain disadvantages. The number of cycles, in which the initial value is estimated, may be affected by nonlinearity (Di Benedetto et al. 2011). Further, the failure of the specimen may occur before achieving a $50 \%$ reduction of the complex modulus, that may be visible from the graph (Lundstrom et al. 2004) or the opposite - the reduced value can be achieved after the crack initiation (Rowe 1993). However, this approach has been used in many studies (Shen \& Lud 2011, Aborjadeh et al. 2007, Tayebali et al. 1993, Pronk \& Hopman 1990).

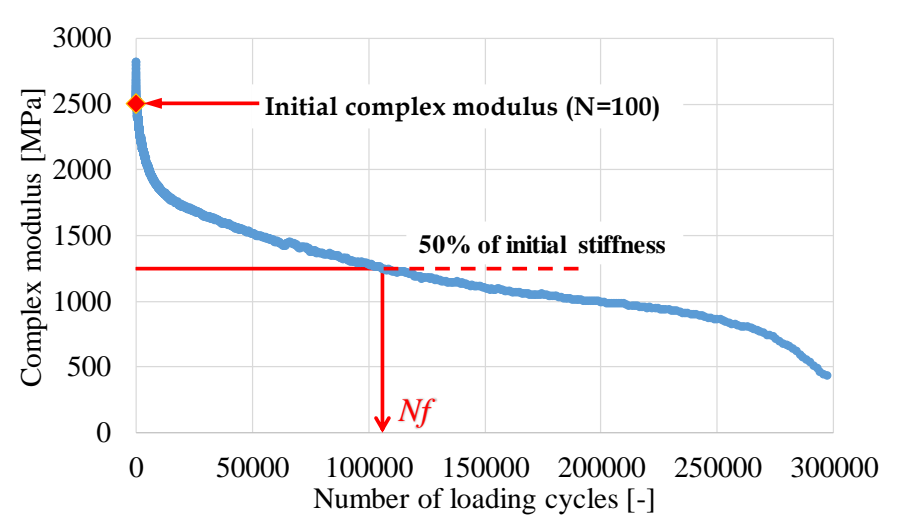

Figure 3: Fatigue life according to the conventional approach

\subsection{Energy ratio approach}

Hopman et al. (1989) introduced the ER approach, in which the failure in a strain-controlled test is defined as the number of cycles (N1) up to the point at which cracks are considered to initiate. The energy ratio is defined as

$R_{E}=\frac{n W_{o}}{W_{n}}=\frac{n\left[\pi \sigma_{0} \epsilon_{0} \sin \varphi_{0}\right]}{\pi \sigma_{n} \epsilon_{n} \sin \varphi_{n}}$

where $n$ is the number of cycles, $W_{0}$ and $W_{\mathrm{n}}$ are the dissipated energy in the first and $n$-th cycle, respectively, $\sigma_{0}$ and $\sigma_{\mathrm{n}}$ are stress levels in the first and $n$-th cycle, respectively, $\epsilon_{0}$ and $\epsilon_{\mathrm{n}}$ are strain levels in the first and $n$-th cycle, respectively, and $\varphi_{0}$ and $\varphi_{\mathrm{n}}$ are phase angles in the first and $n$-th cycle, respectively.

Rowe (1993) considered strain as constant during strain-controlled tests and replaced stress with the product of the strain and modulus, obtaining a simplified equation for calculating the energy ratio $\left(R_{\epsilon}\right)$ :

$R_{\epsilon} \cong \frac{n}{E_{n}^{*}}$

where $n$ is the number of load cycles and $E_{n}^{*}$ is the complex modulus in the $n$-th cycle [MPa].

Using the same basis for simplifying Equation 1, the reduced energy ratio in a stress-controlled test $(\mathrm{R} \sigma)$ can be defined using the following equation:

$R_{\sigma} \cong n \cdot E_{n}^{*}$

where $n$ is number of load cycles and $E_{n}^{*}$ is the complex modulus in the $n$-th cycle [MPa]

In a stress-controlled test, the load amplitude remains constant and after crack initiation the stress at the crack tip increases rapidly (Rowe 1993). The number of cycles $\mathrm{N} 1$ can be determined from the peak value of the $R_{\sigma}$ curve (Fig. 4 ). 


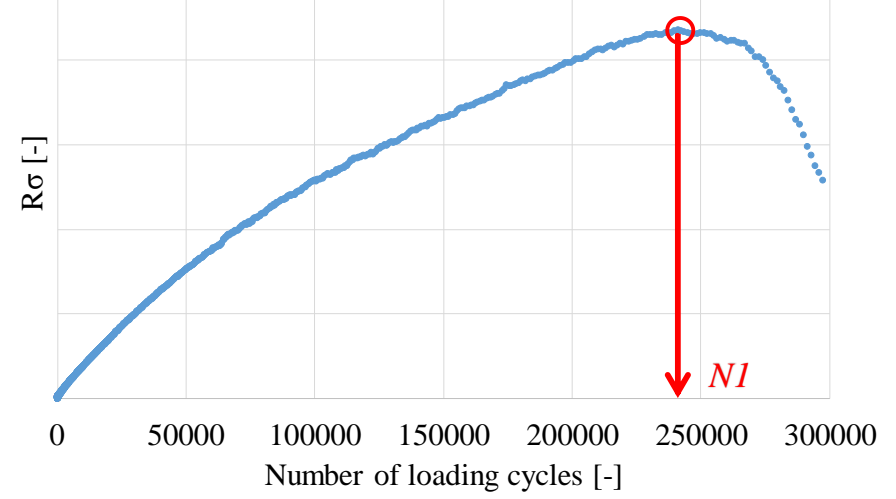

Figure 4: Fatigue life according to the ER approach

\section{RESULTS AND ANALYSIS}

Fatigue tests were performed on nine RF and nine URF specimens, with three specimens tested at each stress level, in order to determine the fatigue life. There was no visible delamination of the beams during testing, since a bitumen emulsion was not used as a tack coat between asphalt layers.

The 4PB fatigue test results of RF and URF specimens, analysed using conventional and ER approach, are shown in Tables 3 and 4. It can be concluded that RF specimens had lower initial values of the complex modulus and higher values of initial strain, which may be a consequence of the weaker bond between layers due to the presence of the glasgrid.

Although RF specimens had higher initial strain than URF specimens, they had a longer life regardless the failure criterion, with the exception of specimens which were tested at the medium stress level, the results of which were analysed using the ER criterion. The results lead to the conclusion that the glasgrid dissipated horizontal stresses from the lower layer, improving fatigue resistance. However, it should be mentioned that the fatigue life of asphalt specimens strongly depends on the chosen failure criterion.

Table 3. 4PB fatigue test results of URF specimens

\begin{tabular}{|c|c|c|c|c|c|}
\hline \multirow[t]{2}{*}{ ID } & \multirow{2}{*}{$\begin{array}{l}\text { Air } \\
\text { void } \\
\text { con- } \\
\text { tent }\end{array}$} & \multirow{2}{*}{$\begin{array}{l}\text { Initial } \\
\text { complex } \\
\text { modulus } \\
(\mathrm{N}=100)\end{array}$} & \multirow[t]{2}{*}{$\begin{array}{l}\text { Initial } \\
\text { strain } \\
(\mathrm{N}=100)\end{array}$} & \multicolumn{2}{|c|}{$\begin{array}{l}\text { Average number of } \\
\text { loading to failure cy- } \\
\text { cles per stress level }\end{array}$} \\
\hline & & & & $\mathrm{Nf}(50 \%)$ & N1 (ER) \\
\hline$[-]$ & {$[\%]$} & [MPa] & {$[\mu \mathrm{m} / \mathrm{m}]$} & {$[-]$} & {$[-]$} \\
\hline $4-2^{1}$ & 6.1 & 2259 & 392 & & \\
\hline $6-2^{1}$ & 6.2 & 2245 & 395 & 14252 & 24433 \\
\hline $2-1^{1}$ & 5.4 & 2401 & 369 & & \\
\hline $2-6^{2}$ & 6.1 & 2503 & 262 & & \\
\hline $2-2^{2}$ & 5.5 & 2418 & 261 & 118013 & 286962 \\
\hline $6-3^{2}$ & 5.6 & 2513 & 272 & & \\
\hline $2-4^{3}$ & 5.8 & 2558 & 214 & & \\
\hline $2-5^{3}$ & 6.0 & 2726 & 216 & 1142494 & 1689479 \\
\hline $2-3^{4}$ & 5.5 & 2756 & 203 & & \\
\hline
\end{tabular}

Applied stresses: ${ }^{1} 0.850 \mathrm{MPa},{ }^{2} 0.650 \mathrm{MPa},{ }^{3} 0.550 \mathrm{MPa},{ }^{4} 0.590$ MPa
Table 4. 4PB fatigue test results of RF specimens

\begin{tabular}{llllll}
\hline ID & $\begin{array}{l}\text { Air } \\
\text { void } \\
\text { con- } \\
\text { tent }\end{array}$ & $\begin{array}{l}\text { Initial } \\
\text { complex } \\
\text { modulus } \\
(\mathrm{N}=100)\end{array}$ & $\begin{array}{l}\text { Initial } \\
\text { strain } \\
(\mathrm{N}=100)\end{array}$ & $\begin{array}{l}\text { Average number of } \\
\text { loading to failure cy- } \\
\text { cles per stress level }\end{array}$ \\
\cline { 5 - 6 } & & $\mathrm{Nf}(50 \%)$ & $\mathrm{N} 1(\mathrm{ER})$ \\
\hline$[-]$ & {$[\%]$} & {$[\mathrm{MPa}]$} & {$[\mu \mathrm{m} / \mathrm{m}]$} & {$[-]$} & {$[-]$} \\
\hline $5-6^{1}$ & 5.8 & 2154 & 410 & & \\
$3-6^{1}$ & 6.1 & 2168 & 410 & 14653 & 28170 \\
$1-3^{1}$ & 5.7 & 2034 & 436 & & \\
\hline $1-6^{2}$ & 5.8 & 2307 & 283 & & \\
$3-5^{2}$ & 6.3 & 2316 & 282 & 135043 & 266416 \\
$5-4^{2}$ & 5.8 & 2271 & 289 & & \\
\hline $5-3^{3}$ & 5.8 & 2760 & 219 & & \\
$1-2^{4}$ & 5.8 & 2469 & 228 & 1281530 & 2428297 \\
$5-2^{4}$ & 6.3 & 2427 & 233 & & \\
\hline Applied stresses: ${ }^{1} 0.850 \mathrm{MPa},{ }^{2} 0.650 \mathrm{MPa},{ }^{3} 0.590 \mathrm{MPa},{ }^{4} 0.550$ \\
$\mathrm{MPa}$
\end{tabular}

The fatigue lines were drawn by performing a linear regression between the natural logarithms of the initial strain after the 100th cycle, as an independent variable, and the number of loading cycles (N1 or Nf), as a dependent variable (EN 12697-24:2012). The laboratory data were used in the model according to the following expression:

$\ln (N)=q+p \times \ln \left(\varepsilon_{i}\right)$

where $N$ is the number of loading cycles leading to failure, $q$ is a coefficient and $p$ is the slope of the regression line and $\varepsilon_{\mathrm{i}}$ is the initial strain, measured at the 100th cycle.

Using the data from Tables 3 and 4, fatigue lines were calculated for both URF and RF specimens, using the conventional approach. Fatigue lines are shown in Figure 5 and described in Equations 5 and 6.

$$
\begin{aligned}
& \ln \left(N_{U R F, 50 \%}\right)=49.94-6.80 \times \ln \left(\varepsilon_{i}\right) \\
& \ln \left(N_{R F, 50 \%}\right)=50.11-6.73 \times \ln \left(\varepsilon_{i}\right)
\end{aligned}
$$

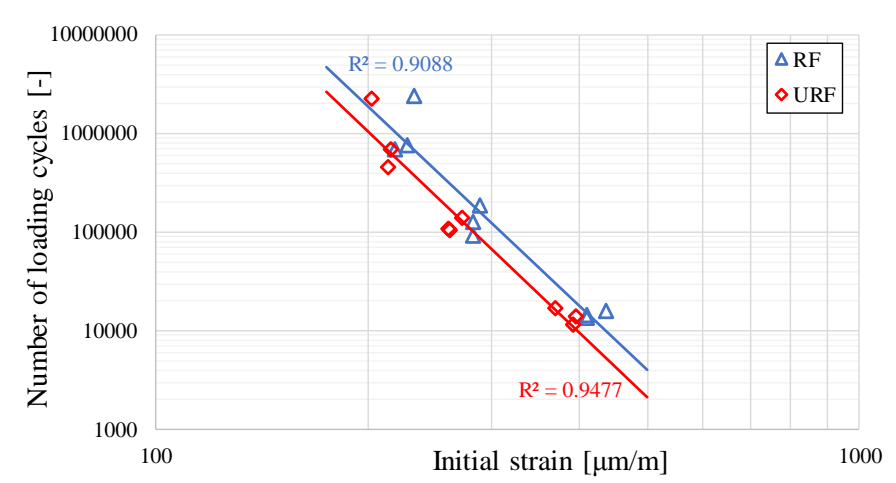

Figure 5. Fatigue lines of URF and RF specimens (conventional approach)

The tensile strain that leads to a fatigue life of $10^{6}$ cycles, calculated using Equations 5 and 6 is equal to $\varepsilon_{6}=202.1 \mu \mathrm{m} / \mathrm{m}$ for the URF set and $\varepsilon_{6}=220.7$ $\mu \mathrm{m} / \mathrm{m}$ for the RF set. Consequently, the use of a glasgrid increases $\varepsilon_{6}$ by $9.2 \%$ and fatigue life by $71.9 \%$ if $\varepsilon_{6}=202.1 \mu \mathrm{m} / \mathrm{m}$ is considered as the critical tensile strain. 
Fatigue lines for both sample sets according to the ER approach are shown in Figure 6 and described in Equation 7 (URF set) and Equation 8 (RF set).

$\ln \left(N_{U R F, E R}\right)=50.35-6.77 \times \ln \left(\varepsilon_{i}\right)$
$\ln \left(N_{R F, E R}\right)=50.93-6.76 \times \ln \left(\varepsilon_{i}\right)$

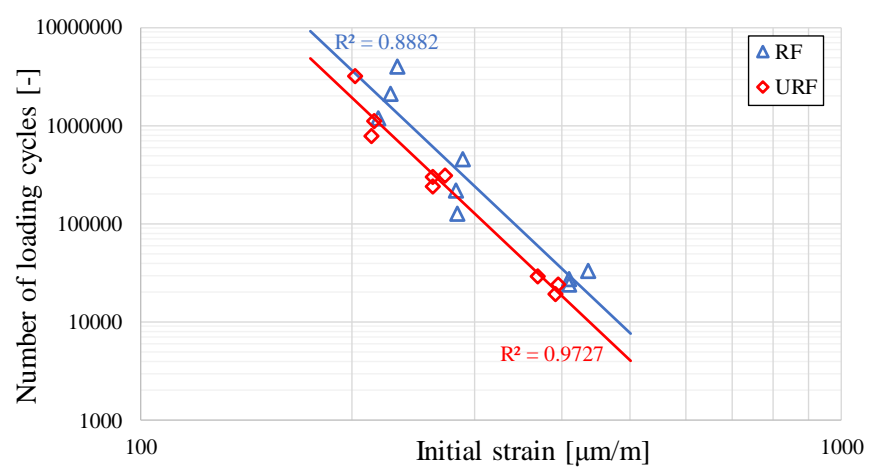

Figure 6. Fatigue lines of URF and RF sample sets (ER approach)

Tensile strain calculated using Equations 7-8 was calculated as $\varepsilon_{6}=221.3 \mu \mathrm{m} / \mathrm{m}$ for the URF set and $\varepsilon_{6}=243.1 \mu \mathrm{m} / \mathrm{m}$ for the RF set. From the comparison of $\varepsilon 6$ values, it can be seen that the glasgrid increases E6 by $9.8 \%$ and the fatigue life by $88.5 \%$ for the critical tensile strain $\varepsilon_{6}=221.3 \mu \mathrm{m} / \mathrm{m}$.

The slopes of the fatigue lines are similar between different sets, regardless the failure criterion.

The influence of the glasgrid on the fatigue life of asphalt samples was determined for three initial strain levels which cover the range of initial strains used for fatigue tests (Tables 3 and 4). Table 5 presents the predicted lives of both URF and RF sets depending on the initial strain level and failure criterion, while the differences between fatigue lives of both sets are depicted in Figure 7.

Table 5. Predicted fatigue lives of URF and RF sets according to the conventional and ER approaches

\begin{tabular}{lllll}
\hline \multirow{2}{*}{$\begin{array}{l}\text { Initial } \\
\text { strain } \\
{[\mu \mathrm{m} / \mathrm{m}]}\end{array}$} & \multicolumn{2}{l}{$\begin{array}{l}\text { Predicted fatigue life } \\
\text { of the URF set }\end{array}$} & \multicolumn{2}{l}{$\begin{array}{l}\text { Predicted fatigue life } \\
\text { of the RF set }\end{array}$} \\
\cline { 2 - 5 } & $\mathrm{Nf}(50 \%)$ & $\mathrm{N} 1(\mathrm{ER})$ & $\mathrm{Nf}(50 \%)$ & $\mathrm{N} 1(\mathrm{ER})$ \\
\hline 220 & $5.76 \cdot 10^{5}$ & $9.95 \cdot 10^{5}$ & $1.02 \cdot 10^{6}$ & $1.92 \cdot 10^{6}$ \\
275 & $1.26 \cdot 10^{5}$ & $2.22 \cdot 10^{5}$ & $2.25 \cdot 10^{5}$ & $4.25 \cdot 10^{5}$ \\
400 & $9.88 \cdot 10^{3}$ & $1.78 \cdot 10^{4}$ & $1.78 \cdot 10^{4}$ & $3.38 \cdot 10^{4}$ \\
\hline
\end{tabular}

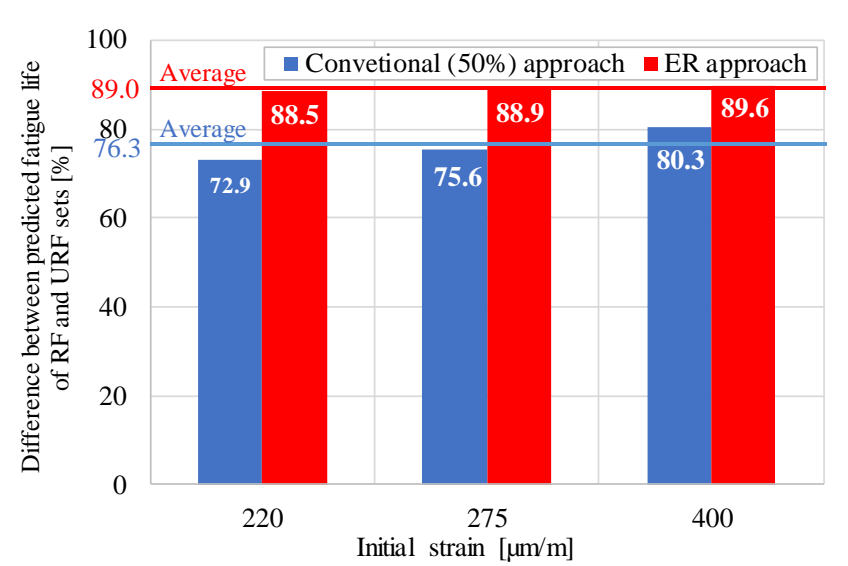

Figure 7. Difference between predicted fatigue lives of RF and URF set depending on the initial strain and failure criterion
The predicted fatigue lives of both RF and URF sets are almost twice higher when the ER approach is used, compared with the conventional approach. The glasgrid increased fatigue life of double-layered asphalt beams by $76.3 \%$ and $89 \%$ according to the conventional and ER approaches, respectively, with values for the ER approach being more consistent and less dependent on the initial strain. Overall results show that the use of glasgrid slows down fatigue crack propagation and that glasgrid behaves as reinforcement in the asphalt pavement structure.

\section{CONCLUSIONS}

In this study, the 4PB fatigue test was used to characterize the fatigue resistance of double-layered beams reinforced with a self-adhesive glasgrid (RF specimens), positioned $30 \mathrm{~mm}$ from the top and $20 \mathrm{~mm}$ from the bottom, and without a tack coat between layers. This resistance was compared with the fatigue resistance of unreinforced double-layered beams (URF specimens) of the same dimensions (400L x 60W x $50 \mathrm{H} \mathrm{mm}$ ), also constructed without a tack coat. Obtained test results were analyzed using two failure criteria: a conventional approach in which fatigue life is expressed as the number of cycles (Nf) leading to $50 \%$ reduction of the initial stiffness modulus, and an ER approach in which fatigue life was expressed as the number of cycles (N1) leading to the initiation of cracking.

The influence of the glasgrid on fatigue resistance of asphalt concrete beams was determined by comparing the fatigue lines of URF and RF specimens. The comparison showed the following:

- The use of glasgrid increases fatigue life of asphalt layers by $76.3 \%$ and $89 \%$ when conventional and ER failure criteria are used, respectively;

- The tensile strain $\varepsilon 6$ increases by $9.2 \%$ and $9.8 \%$ when the conventional and ER approaches are used, respectively;

- The fatigue line slopes are similar between sets, regardless the failure criteria;

- The fatigue life of double-layered asphalt beams depends on the failure criterion: the ER approach predicts almost a twice longer life than the conventional approach.

Test results showed that the glasgrid dissipates horizontal stresses induced by the cracks and delays fatigue crack propagation, improving the fatigue resistance of the asphalt beams. However, it should be mentioned that tested beams were observed as a homogenous layers and that a tack coat was not applied between layers, making the interface between layers as "weak" place within the system. In this case bonding and interlock of the glasgrid and surrounding layers where achieved to enhance fatigue life. Nevertheless, the use of an appropriate tack coat and correct 
dosage would lead to additional extension of fatigue life.

Future studies should be focused on the assessment of glasgrid benefit when the complex modulus is reduced more than $50 \%$. In this stage, reinforcement benefit is maximally introduced that improves the cracking resistance.

\section{ACKNOWLEDGMENTS}

The work reported in this paper is supported by SaintGobain Adfors CZ. This support is gratefully acknowledged.

\section{REFERENCES}

Abojaradeh M. 2013. Development of Fatigue Failure Criterion for Hot-Mix Asphalt Based on Dissipated Energy and Stiffness Ratio. Jordan Journal of Civil Engineering, 7(1): 54-69

Abojaradeh, M., Witczak, M., Mamlouk, M. \& Kaloush, K. 2007. Validation of Initial and Failure Stiffness Definitions in Flexure Fatigue Test for Hot-Mix Asphalt. ASTM Journal of Testing and Evaluation 35: 95-102

Arsenie, I.M., Chazallon, C., Duchez, J. L. \& Doligez, D. 2004. Fatigue behaviour of an asphalt concrete reinforced with glass fiber grid with 4PB test. In Kim, Y. (ED). Asphalt pavements; North Carolina, US, 1-5 June 2014: 1301-1309. London: CRC Press

Arsenie, I.M., Chazallon, C., Duchez, J. L. \& Hornych, P. 2016. Laboratory characterisation of the fatigue behaviour of a glass fibre grid-reinforced asphalt concrete using 4PB tests. Road Materials and Pavement Design 18(1): 168-180

Di Benedetto, H., Nguyen, Q.T. \& Sauzeat, C. 2011. Nonlinearity, Heating, Fatigue and Thixotropy during Cycling Loading of Asphalt Mixtures. Road Materials and Pavement Design 12(1): $129-158$

EN 12697-24: 2012 - Bituminous mixtures - Test methods - Part 24: Resistance to fatigue

Graziani, A., Sangiorgi, C. \& Canestrari, F. 2016. Fracture Characterization of Grid-Reinforced Asphalt Pavements. In Chabot A., Buttlar, W., Dave, E., Petit, C. and Tebaldi, G (eds.), $8^{\text {th }}$ RILEM International Conference on Mechanisms of Cracking and Debonding in Pavements, RILEM Bookseries, vol 13. Springer, Dordrecht

Hopman, P.C., Kunst, P.A.J.C. \& Pronk, A.C. 1989. A Renewed Interpretation Method for Fatigue Measurement, Verification of Miner's Rule. In proceeding of $4^{\text {th }}$ Eurobitumen Symposium, Volume 1, 4-6 October; Madrid, Spain: 557-561

Lundstrom, R., Di Benedetto, H. \& Isacsson U. 2004. Influence of asphalt mixture stiffness on fatigue failure. Journal of materials in civil engineering 16(6): 516-525

Nguyen, M.L., Blanc, J., Kerzrého, J.P. \& Hornych, P. 2013. Review of glass fibre grid use for pavement reinforcement and APT experiments at IFSTTAR. Road Materials and Pavement Design, 14(sup1): 287-308

Pasquini, E., Bocci, M., Ferroti, G. \& Canestrari, F. 2013. Laboratory characterisation and field validation of geogrid-reinforced asphalt pavements. Road Materials and Pavement Design, 14(1): 17-35

Pronk, A.C. \& Hopman, P.C. 1990. Energy dissipation: the leading factor of fatigue. In proceedings of Highway Research: Sharing the Benefits. The United States Strategic Highway Research Program, 29-31 October; London, England: 255267
Romeo, E. \& Montepara, A. 2012. Characterization of reinforced asphalt pavement cracking behavior using flexural analysis. Procedia - Social and Behavioral Sciences 53: 356-365

Rowe G. M. 1993. Performance of Asphalt Mixtures in the Trapezoidal Fatigue Test. In Proceedings of the Association of Asphalt Paving Technologist, Volume 62, Austin, Texas: 344-384

Rowe, G.M., Blankenship, P., Sharrock, M. \& Bennert, T. 2012. The fatigue performance of asphalt mixtures in the four point bending beam fatigue test in accordance with AASHTO and ASTM analysis method. In Proceeding of the $5^{\text {th }}$ Eurasphalt \& Eurobitume Congress, Istanbul, Turkey, 13-15 June 2012

Shen S. \& Lu X. 2011. Energy-Based Laboratory Fatigue Failure Criteria for Asphalt Materials. ASTM Journal of Testing and Evaluation 39: 1-8

Tayebali, A. A., Deacon, J. A., Coplantz, J. S. \& Monismith C. L. 1993. Modelling Fatigue Response of Asphalt-Aggregate Mixes. Journal of the Association of Asphalt Paving Technologists 62: 385-421

Van Dijk, W. \& Visser, W. 1977. The Energy Approach to Fatigue for Pavement Design. In Proceedings of the Association of Asphalt Paving Technologist, 21-23 February; San Antonio, Texas: 1-40

Virgili, A., Canestrari, F., Grilli, A. \& Santagata, F.A. 2009. Repeated load test on bituminous systems reinforced by geosynthetics. Geotextiles and Geomembranes 27: 187-195 